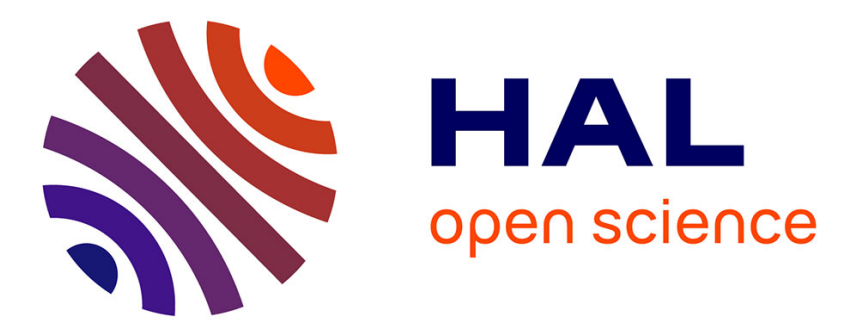

\title{
Species-specific diversity in the anatomical and physiological organisation of the BNST-VTA pathway
}

Jennifer Kaufling, Delphine Girard, Marlène Maitre, Thierry Leste-Lasserre, F Georges

\section{- To cite this version:}

Jennifer Kaufling, Delphine Girard, Marlène Maitre, Thierry Leste-Lasserre, F Georges. Speciesspecific diversity in the anatomical and physiological organisation of the BNST-VTA pathway. European Journal of Neuroscience, 2017, 45 (9), pp.1230-1240. 10.1111/ejn.13554 · hal-03130431

\section{HAL Id: hal-03130431 \\ https://hal.science/hal-03130431}

Submitted on 3 Feb 2021

HAL is a multi-disciplinary open access archive for the deposit and dissemination of scientific research documents, whether they are published or not. The documents may come from teaching and research institutions in France or abroad, or from public or private research centers.
L'archive ouverte pluridisciplinaire HAL, est destinée au dépôt et à la diffusion de documents scientifiques de niveau recherche, publiés ou non, émanant des établissements d'enseignement et de recherche français ou étrangers, des laboratoires publics ou privés. 
Species-specific diversity in the anatomical and physiological organization of the BNST-VTA pathway.

Jennifer Kaufling ${ }^{1,2,3}$, Delphine Girard ${ }^{1,2}$, Marlène Maitre ${ }^{4}$, Thierry Leste-Lasserre ${ }^{4}$ and François Georges ${ }^{5,6}$

\section{Author Affiliations:}

1 Université de Bordeaux, Interdisciplinary Institute for Neuroscience, UMR5297, F33076 Bordeaux, France.

${ }^{2}$ Centre National de la Recherche Scientifique, Interdisciplinary Institute for Neuroscience, UMR 5297, F-33076 Bordeaux, France.

${ }^{3}$ Current affiliation: MRC Brain Network Dynamics Unit. University of Oxford. Mansfield Road. Oxford OX1 3TH. UK

${ }^{4}$ INSERM, Neurocentre Magendie U1215, F-33076 Bordeaux, France.

${ }^{5}$ Université de Bordeaux, Neurodegeneratives Diseases Institute, UMR 5293, F33076 Bordeaux, France.

${ }^{6}$ Centre National de la Recherche Scientifique, Neurodegeneratives Diseases Institute, UMR 5293, F-33076 Bordeaux, France.

Abbreviated title: Specificities of the BNST-VTA in mice versus rats

Correspondence should be addressed to: François Georges, E-mail: francois.georges@u-bordeaux.fr

Number of figures: 6

Number of tables: 1

Number of words:

Abstract: 239

Introduction: 642

Discussion: 1382

Acknowledgements 
This work was supported by grants from Centre National de la Recherche Scientifique (CNRS), University of Bordeaux, Agence Nationale de la Recherche (ANR-12-BSV4-0022 to F.G.), by LABEX BRAIN ANR-10-LABX-43 and Region Aquitaine. We thank Drs. Michel Barrot and Amy Wolff for helpful discussions and English editing regarding this manuscript. We thank Drs Muriel Koehl and Nora Abrous for help with the cell counting experiments.

\section{AUTHOR CONTRIBUTIONS}

J.K. and F.G. designed the experiments. J.K. performed the anatomical and in vivo electrophysiological experiments, and analyzed the data. D.G. M.M and T.L-L. performed the qRT-PCR and microdissection experiments. J.K. and F.G. wrote the manuscript. All authors discussed the results and commented the manuscript. 


\begin{abstract}
The anteromedial part of the bed nucleus of the stria terminalis (amBNST) is a limbic structure innervating the ventral tegmental area (VTA) that is remarkably constant across species. The amBNST modulates fear and anxiety, and activation of VTA dopamine (DA) neurons by amBNST afferents seems to be the way by which stress control motivational states associated to reward or aversion. Because fear learning and anxiety state can be expressed differently between rats and mice, we compared the functional connectivity between amBNST and the VTA-DA neurons in both species using constant methodological approaches. Using a combination of in vivo electrophysiological, neuroanatomical tracing and laser capture approaches we explored the BNST influence on VTA-DA neurons activity. First, we characterized in rats the molecular phenotype of the amBNST neurons projecting to the VTA. We found that this projection is complex, including both GABAergic and glutamatergic neurons. Then VTA injections of a conventional retrograde tracer, the $\beta$-sub-unit of the cholera toxin (CTB), revealed a stronger BNST-VTA projection in mice than in rats. Finally, electrical stimulations of the BNST during VTA-DA neurons recording demonstrated a more potent excitatory influence of the amBNST on VTA-DA neurons activity in rats than in mice. These data illustrate, anatomically but also functionally, a significant difference between rats and mice in the amBNST-VTA pathway. More generally, together with previous findings, our research highlights the importance of species differences for the interpretation and the generalization of research data.
\end{abstract}




\section{Significance}

We show inter-species differences in the anatomical and physiological organization of the pathway linking the anteromedial part of the bed nucleus of the stria terminalis (amBNST) and the dopaminergic (DA) neurons of the ventral tegmental area (VTA). These differences concern the density of amBNST neuronal projection to the VTA (mice > rats) and the overall electrophysiological response of VTA DA neuron to BNST stimulation (rats > mice). No differences were observed between rats and mice in the amBNST neuronal density, in the cell-type diversity of VTA-projecting BNST neurons, in the basal firing properties of VTA DA neurons. This study highlights the importance of species differences for the interpretation and the generalization of research data. 


\section{Introduction}

The bed nucleus of the stria terminalis (BNST) is a limbic centre of integration involved in a large array of behaviours including stress responses, anxiety, fear states, and social behaviour (For review: Daniel and Rainnie 2016; Lebow and Chen 2016). The BNST is a complex structure consisting of 12 to 18 nuclei divided into anterior and posterior divisions (Moga et al., 1989; Ju et al., 1989 a-b). Another degree of complexity is revealed by the diversity of the neuronal population, especially in the anteromedial nucleus (amBNST), the region, which this study focuses on. The amBNST is mainly composed of GABAergic neurons expressing a variety of peptides, receptors or transporters in many combinations and and by a smaller population of glutamatergic projection neurons (for review: Gungor and Pare, 2016). Finally, a third level of complexity is found through the vast connectivity networks of this structure (for review: Gungor and Pare, 2016). The projection from the amBNST to the VTA has recently attracted attention and has brought to light the role of the amBNST as an interface between stress and motivational / reward systems (Georges and Aston-Jones 2001-2002; Dong et al., 2004; Dumont et al., 2004; Geisler et Zahm, 2005; Jalabert et al., 2009; Kudo et al., 2012; 2014; Massi et al., 2008; Jennings et al., 2013). This pathway seems to be anatomically preserved during evolution through mice (Kudo et al., 2012; Jennings et al., 2013) and rats (Georges and Aston-Jones 2001-2002). However, there are conflicting reports on the neurochemical sources and neuronal targets of this projection in rodents. Even if it appears clear that glutamatergic and GABAergic BNST neurons project to the VTA (Kudo et al., 2012-2014), which of these neural populations prevails and what's the net effect of this pathway on VTA DA neurons activity remains unclear. Aston-Jones and Georges described a predominance of a direct BNST excitatory influence (glutamatergic) on VTA DA neurons (Georges and Aston-Jones 2001-2002; Massi et al., 2008; Jalabert et al., 2009), whereas Stuber and Watanabe suggested a predominance of BNST GABAergic (inhibitory influence) on VTA GABAergic neurons which subsequently would lead to a disinhibition of VTA DA cells (Jennings et al., 2013; Kudo et al., 2012-2014). Whether these contrasting results reflect species or methodological differences remains unclear as ex vivo versus in vivo recordings were used in mice and rats respectively. The present study was undertaken to address this issue by tracing the amBNST-VTA pathway and recording the response 
of VTA DA neurons to amBNST stimulation in rats and mice, using identical in vivo methodological approaches.

Overall, our results indicate that there are marked species differences in the organization of the amBNST-VTA pathway. At anatomical level, we found that although there was a similar BNST neuronal density across species, a much larger population of BNST neurons projected to the VTA in mice than in rats. At molecular level, we observed, in rats, the presence of both glutamatergic and GABAergic BNST neuronal populations efferent to the VTA, as has been previously reported in mice (Kudo et al., 2012; 2014). Using in vivo electrophysiology, we observed similar basal activity in rats and mice, but different early responses to BNST stimulation. We showed that the proportion of excited neurons in rats is more than double the one observed in mice, suggesting a larger excitatory BNST influence on rat VTA DA neurons. Finally, using a pre / post stimulation method's analysis, we evaluated the overall potential effect of BNST stimulation on the VTA DA neuronal population. Intriguingly, we find another striking difference between species; in rats, BNST stimulation induces an early excitation of VTA DA neuronal population, whereas it induces a smaller, early inhibition in mice.

Collectively, these differences between mice and rats could reconcile many of the inconsistencies observed in the literature, but mainly highlight the importance of taking into account the choice of animal model for experiments and interpretation. 


\section{Materials and Methods}

\section{Animals}

Results were obtain from 22 male Sprague-Dawley rats (300-400g, Janvier laboratory; 8 for anatomical procedures; 6 for molecular procedure and 8 for electrophysiology procedures) and 20 male C56BL/6J mice (Two-three month old, Janvier laboratory; 8 for anatomical procedures and 12 for electrophysiology procedures). Animal were housed $\left(22-23^{\circ} \mathrm{C}\right.$; $12 / 12$ light-dark cycle, lights on $7 \mathrm{am}$ ) with food and water available ad libitum. All procedures were conducted in accordance with the European directive 2010-63-EU and with approval from the Bordeaux University Animal Care and Use Committee N 50120206-A.

\section{Surgery}

Animals were first anesthetized with $4 \%$ isoflurane $1 \mathrm{~L} / \mathrm{min}$ air and $\mathrm{O}_{2}$ for induction, and placed in the stereotaxic frame. $1.5 \%$ isoflurane $1 \mathrm{~L} / \mathrm{min}$ air and $\mathrm{O}_{2}$ was delivered through a facial mask via spontaneous respiration during surgical procedures and recording. Body temperature was maintained at $36-38^{\circ} \mathrm{C}$ with a thermistor-controlled electric heating pad during the procedure. For VTA tracer injection and recording, the skull was exposed, and holes were drilled above the VTA (rat: $-5.6 \mathrm{~mm}$ caudal to bregma, $0.6 \mathrm{~mm}$ lateral to bregma and $7.2 \mathrm{~mm}$ ventral to dura; mouse: $-3.4 \mathrm{~mm}$ caudal to bregma, $0.4 \mathrm{~mm}$ lateral to bregma and $4.4 \mathrm{~mm}$ ventral to dura). For BNST electrical stimulation during electrophysiology procedures, a second hole was drilled above the BNST (rat: $-0.1 \mathrm{~mm}$ caudal to bregma, $1.3 \mathrm{~mm}$ lateral to bregma and $6.8 \mathrm{~mm}$ ventral to dura; mouse: $-0.15 \mathrm{~mm}$ caudal to bregma, $0.8 \mathrm{~mm}$ lateral to bregma and $4.2 \mathrm{~mm}$ ventral to dura).

\section{Electrophysiological methods}

A glass micropipette (1-3 $\mathrm{m}, 6-12 \mathrm{M} \Omega$ ) filled with $2.0 \%$ pontamine sky blue in $0.5 \mathrm{M}$ sodium acetate was used for VTA recording. The extracellular potential was recorded with an Axoclamp 900A amplifier in the bridge mode versus a reference electrode maintained in contact with the skull by a sponge moistened with a $0.9 \%$ $\mathrm{NaCl}$ solution. The extracellular potential amplified $10 \times$ by the Axoclamp amplifier was further amplified 100x and filtered (low-pass filter at $300 \mathrm{~Hz}$ and high-pass filter 
at $10 \mathrm{kHz}$ ) via a differential AC amplifier (model 1700; A-M Systems). Spikes of single neurons were discriminated, and digital pulses were sent to a computer for online data collection with a laboratory interface and software (CED 1401, Spike2; Cambridge Electronic Design, Cambridge, UK). Only spontaneously active neurons were recorded and analysed. Putative VTA DA neurons were recorded for 2 min to establish a mean baseline firing rate before any BNST electrical stimulation. Bipolar electrical stimulation of the BNST was conducted with a concentric electrode (250 $\mu \mathrm{m}$ diameter overall, $100 \mu \mathrm{m}$ diameter inner electrode which extended $100 \mu \mathrm{m}$ beyond the outer electrode; Phymep). Electrical stimulation $(0.5-1.5 \mathrm{~mA}, 0.5 \mathrm{~Hz}, 0.5$ msec duration pulses, 100 repetitions) was administered using a square pulse stimulator (CED 1401, SPIKE 2; Cambridge Electronic Design) and stimulus isolator (ISO-Flex; A.M.P.I.).

For VTA recordings, electrophysiological criteria used to identify putative DA neurons were similar to previous studies (Ungless and Grace 2012; Grace and Bunney, 1984a,b; Ungless et al., 2004). These included (1) action potential with biphasic or triphasic waveform $\geq 2.5 \mathrm{msec}$ in duration, (2) $\geq 1.1 \mathrm{msec}$ from spike onset to negative trough, and (3) slow spontaneous firing rate $<10$ spikes/second. At the end of each recording experiment, recording electrode placement in the VTA was marked with an iontophoretic deposit of pontamine sky blue dye $(-10 \mu \mathrm{A}$, pulsed current for $30 \mathrm{~min}$ ) and BNST stimulation electrode placement was marked by electrical lesion (+50 $\mu \mathrm{A}$, pulsed current for $1 \mathrm{~min})$. After the experimental procedures, the animals were deeply anesthetized with isoflurane (5\%) and decapitated. Brains were removed and snap-frozen in a solution of isopentane at $-80^{\circ} \mathrm{C}$. Coronal, $40 \mu \mathrm{m}$-thick sections were cut on a cryostat and counterstained with neutral red (Fisher, Fairlawn, NJ, USA), dehydrated with graded alcohol solutions, cleared with xylene and coverslipped with Eukitt. Histological localization of VTA recording and BNST stimulation sites, allowed us to verified the localisation of ours electrodes.

\section{Electrophysiological analysis}

To compare basal firing rates of putative VTA DA neurons between rats and mice, each cell was recorded for at least $120 \mathrm{sec}$. In addition, burst analysis was performed. The onset of a burst was defined as the occurrence of two spikes with an interspike interval < $80 \mathrm{~ms}$ (Grace and Bunney, 1984a). We evaluated the amount of 
bursting activity by calculating the bursting rate (number of burst events by second) and the mean spike per burst.

To analyse the effect of BNST stimulation on VTA DA neuron, cumulative peristimulus time histograms (PSTHs, $5 \mathrm{~ms}$ bin width, 100 stimulations) of VTA activity were generated for each putative VTA DA recorded neuron. PSTHs were analysed to determine inhibitory and excitatory epochs as described previously (Georges and Aston-Jones, 2002; Moorman and Aston-Jones, 2010). The mean and standard deviation (SD) of counts per bin were determined for a baseline period (500 ms epoch preceding stimulation). In order to focus on the direct BNST VTA pathway, we only analysed inhibition and excitation starting on the first $15 \mathrm{~ms}$ after BNST stimulation. Inhibition onset was defined as an epoch of at least 2 bins in which the mean count per bin was at least $30 \%$ less than that during baseline. Significant excitation onset was defined as the first bin for which the mean value exceeded mean baseline activity by 2 SD. Proportion of excitation, inhibition and no effect of VTA DA neurons after BNST stimulation were evaluated for rats and mice and latency of inhibition and excitation between the 2 species were compared.

In second time, to compare the overall effect of BNST stimulation on VTA DA neuronal population in rats and nice, a second set of PSTHs were generated for each putative VTA DA neuron recorded during BNST stimulation (5 msec bin, 250 msec offset, 500 msec lengths, 100 stimulations). For each VTA DA neuron we calculated a ratio of the sum of spikes occurring $250 \mathrm{~ms}$ after the BNST stimulations / the sum of spikes occurring $250 \mathrm{~ms}$ before the BNST stimulation. A ratio value of 1 indicates no effect of BNST stimulation on VTA DA neuron. A value superior to 1 indicate an excitation and a number inferior to 1 an inhibition. Mean ratio between rats and mice were compared.

\section{Tracer injection}

We injected cholera toxin B (CTB; $0.5 \%$ in $0.1 \mathrm{M}$ Tris, $0.1 \% \mathrm{NaCl}$; Sigma) or an undiluted suspension of fluorescent microsphere $(0.04 \mu \mathrm{m}$ diameter, red FluoSpheres; Invitrogen) in the VTA as a retrograde tracer. CTB (20/40 nl) or microbeads $(60 \mathrm{nl})$ were micro-infused via pneumatic pressure (Picospritzer, General Valve) using a glass micropipette (tip diameter: 30-40 $\mu \mathrm{m}$ for CTB, 50-60 for 
microbeads) in rats and mice VTA (microbeads only in rats). A week after CTB injection, animals were perfused with cold $0.9 \% \mathrm{NaCl}$ followed by cold $4 \%$ paraformaldehyde in $0.1 \mathrm{M}$ phosphate buffer (PB). Brains were postfixed overnight in $4 \%$ paraformaldehyde and transferred to a $20 \%$ solution of sucrose $/ 0.1 \%$ sodium azide $(\mathrm{Az})$ in $\mathrm{PB}$ at $4^{\circ} \mathrm{C}$ for at least 3 days. Coronal $40 \mu \mathrm{m}$-thick sections of brains were cut on a cryostat and serially collected in phosphate buffer with $0.9 \% \mathrm{NaCl}$ (PBS). A week after microbeads injection rats were euthanized with isoflurane overdose (Metacam $5 \mathrm{mg} / \mathrm{kg} 30 \mathrm{~min}$ before isoflurane), their brains were dissected, immediately frozen in isopentane and stored at $-80^{\circ} \mathrm{C}$.

\section{Immunochemistry}

For immunohistochemistry, section were washed in PBS (3 $\times 10 \mathrm{~min})$, incubated for $15 \min$ in $1 \% \mathrm{H}_{2} \mathrm{O}_{2} / 50 \%$ ethanol solution if used for peroxidase reaction, washed in PBS ( $3 \times 10 \mathrm{~min}$ ), and incubated in PBS containing $0.3 \%$ Triton $X-100$ and $5 \%$ donkey serum for $45 \mathrm{~min}$. Sections were then incubated overnight at room temperature in PBS with $0.3 \%$ Triton $\mathrm{X}-100,1 \%$ donkey serum, and primary antibody. We used the following antibodies:

Rabbit anti-cholera toxin polyclonal antibody (Sigma, cat. No. C3062; dilution $1: 10,000$ for fluorescence and peroxidase reaction). Mouse anti-tyrosine hydroxylase (TH) polyclonal antibody (Chemicon, cat. No. AB1542; dilution 1:8000 for fluorescent staining). Rabbit anti-Fox3 polyclonal antibody (Abcam, calalogue No. ab104225; dilution 1:1000 for fluorescent staining). Section for immunofluorescence were washed in PBS (3 x $10 \mathrm{~min}$ ), incubated with a donkey Alexa 488 or 593 fluorophorelabelled secondary antibody (Sigma Aldrich; dilution 1:400) for $1 \mathrm{~h} 30 \mathrm{~min}$, and washed in PBS (3 x $10 \mathrm{~min}$ ) before mounting in Vectashield (Vector, Burlingame, CA). Sections for peroxidase reaction were washed in PBS (3 x $10 \mathrm{~min}$ ), incubated with a biotinylated donkey secondary antibody (Amersham Biosciences, Arlington; dilution 1:200) in PBS, $0.3 \%$ Triton X-100, 1\% donkey serum) for $1 \mathrm{~h} 30 \mathrm{~min}$, washed in PBS ( $3 \times 10 \mathrm{~min}$ ), and incubated with PBS containing the avidin-biotin-peroxydase complex (ABC Elite, 2 drops A solution / $\mathrm{ml}$ and 2 drop B solution /ml) for $1 \mathrm{~h} 30 \mathrm{~min}$. After washing in Tris-HCL buffer (0.05 M, pH 7.5; 3 x $10 \mathrm{~min})$, bound peroxidase was revealed by using the 3.3'-diaminobenzidine tetrahydrochloride (DAB) Vector kit (vector). Section were incubated for approximately $10 \mathrm{~min}$ and washed again. 
Finally, sections were serially mounted on gelatine-coated slides, air-dried, dehydrated in graded alcohols, cleared in xylene and coverslipped with Eukitt.

\section{Cell counting and pictures}

\section{BNST neuronal density}

To compare the BNST neuronal density between rat and mice $40 \mu \mathrm{m}$ thick frontal sections at $160 \mu \mathrm{m}$ intervals throughout the BNST were processed for Fox3 immunofluorescence staining (3 rats / 3 mice). A 20x objective was used to acquire 4 $z$ stacks per section (2 per hemisphere) in the BNSTd and BNSTV. After acquisition ImageJ was used to semi automatically quantify the density of neurons (Fox3+) in rats and mice BNSTd and BNSTV. Confocal photomicrographs were acquired with a Leica DMI6000 TCS SP5 STED confocal microscope. Alexa 594 was excited with a Helium/Neon laser.

\section{Density of BNST neuron projecting to the VTA}

The rats and mice comparison of the density of BNST neurons projecting to the VTA were done by counting retrogradelly labelled $(\mathrm{CTB}+)$ neurons in the BNST subnuclei of animals injected with CTB in the VTA. Photographs, counting and drawing of retrograde labelling reveals by peroxidase reaction were done from representative $40 \mu \mathrm{m}$ frontal sections containing BNST of 4 rats and 5 mice, using a Nikon Eclipse 80i microscope with Stereo Investigator system (MicroBrightField, Williston, Vermont).

\section{Picture acquisition}

Sections were examined and photographs with a Hamamatsu NANOZOOMER 2.0HT associate to a TDI 3-CCD camera or a Leica microscope (Leica DM5000 associated with a CCD Coolsnap HQ2 for brightfield and a CCD QImaging QICAM camera for fluorescence). Adobe Photoshop was used to adjust contrast, brightness and sharpness. For fluorescence, the colour channels were individually adjusted for the merged pictures. Abbreviations and structure limits are based on the frontal diagrams from the atlas of Paxinos and Watson, 2007. 


\section{Laser microdissection}

Coronal sections of the BNST and striatum (12 $\mu \mathrm{m}$ thickness) were made using a CM3050 S microtome (Leica) and mounted on polyethyl-ene-naphthalate membrane glass slides (P.A.L.M. Microlaser Technologies AG, Zeiss, Germany) that have been pretreated to inactivate RNase. Subsequently, sections were, dehydrated in a series of pre-cooled ethanol baths (30s in $75 \%, 30$ s in $95 \%$ and twice 40 s in $100 \%$ ) and airdried. Immediately after dehydratation Laser microdissection was performed using a PALM MicroBeam microdissection system version 4.0-1206 equipped with a P.A.L.M. RoboSoftware (P.A.L.M. Microlaser Technologies AG, Zeiss, Germany). The PALM system is based on laser microdissection pressure catapulting (LPC) technology. A high-pressure laser beam ejects the selected sample and catapults it into an Eppendorf cap used with an inverted microscope. At the structure-level, striatum and BNSTov were microdissected at X5 magnification on each slices of brain. At cell-level, after having delimited the BNST at X5 magnification on each slices of brain, red retrobeads were visualized using N2.1 filter $(515-560 \mathrm{~nm})$ at X63 magnification and microdissection was performed.. Samples were collected in adhesives caps (P.A.L.M. Microlaser Technologies AG, Bernried, Germany). These cells were resuspended in a guanidine isothiocyanate-containing buffer (RLT buffer from RNeasy minikit, Qiagen, Chatsworth, CA) with $10 \mu \mathrm{l} / \mathrm{ml} \quad \beta$ mercaptoethanol to ensure isolation of intact RNA and kept at $-20^{\circ} \mathrm{C}$. The integrity and quantity of the RNA was checked by capillary electrophoresis using the RNA 6000 Pico Labchip kit and the Bioanalyser 2100 (Agilent Technologies, Massy, France).

\section{Quantitative real-time PCR (q-PCR)}

cDNA was synthesized from $100 \mathrm{ng}$ of total RNA using RevertAid Premium Reverse Transcriptase (Fermentas) and primed with oligo-dT primers and random primers (Fermentas). qPCR was performed using a LightCycler ${ }^{\circledR} 480$ Real-Time PCR System (Roche, Meylan, France). Reactions were done in duplicate for each sample, using transcript-specific primers, cDNA (4 ng) and LightCycler 480 SYBR Green I Master (Roche) in a final volume of $10 \mu \mathrm{l}$. The PCR data were exported and analyzed using a software (Gene Expression Analysis Software Environment) developed at the NeuroCentre Magendie. Relative expression analysis was 
normalized against two reference genes (Bustin et al., 2009), glyceraldehyde-3phosphate dehydrogenase (Gapdh) and b-actine (Actb) genes were used as reference genes. The relative level of expression was calculated using the comparative $\left(2^{-\Delta \Delta C T}\right)$ method (Livak et al., 2001). Primers sequences are reported in supplementary table 1.

Table 1. Rat qPCR primer sequences.

\begin{tabular}{|c|c|c|c|}
\hline Gene & GenBank ID & Forward Sequence (5'-3') & Reverse Sequence (5'-3') \\
\hline $\begin{array}{l}\text { GAD1 } \\
\text { (GAD67) }\end{array}$ & NM_017007 & CAAACCCATGAGCTGGCTTTA & GGGCTCCTTTGCAGGTGTC \\
\hline $\begin{array}{l}\text { Slc17a6 } \\
\text { (VgluT2) }\end{array}$ & NM_053427 & TGCGCTGATAAGAATGCACATC & CCCAAAACAGACAGGTAAACACAC \\
\hline $\begin{array}{l}\text { Slc17a8 } \\
\text { (VgluT3) }\end{array}$ & NM_153725 & GAGTGTAGGGTCATTTTCAATGACA & CCAAACATGGAATTACCCACAAA \\
\hline Camk2a & NM 012920 & CACATCCACCTGATGGGTGA & CCCGCATCCAGGTACTGAGT \\
\hline Gapdh & NM_017008 & GAATGGGAAGCTGGTCATCAAC & CCATTTGATGTTAGCGGGATCT \\
\hline Actb & NM_031144 & CGGCAATGAGCGGTTC & TGCCACAGGATTCCATACCC \\
\hline
\end{tabular}

\section{Statistical analyses}

In all cases, results are expressed throughout as mean \pm SEM. When two means were compared, the statistical significance of their difference was assessed by twotailed paired Student's $t$ tests. For multiple comparisons, values were subjected to a one-way Anova followed if significant by Tukey's post hoc tests All measurements and analyses were performed in Spike2 (Cambridge Electronic Design), prism or Excel (Microsoft). 


\section{Results}

\section{Similar BNST neuronal density between rats and mice}

In order to compare the BNST-VTA pathway between rats and mice, we first evaluated the BNST neuronal density in both species. We performed immunostaining for Fox3 (to identify neurons) and confocal imaging (Fig. 1A). In the BNSTV and BNSTd, the neuronal population density did not significantly differ between rats and mice (BNSTv: $t_{4}=0.564 p=0.603$, ns; BNSTd: $t_{4}=2.539 p=$ 0.064 , ns; $n=3$ rats, $n=3$ mice) (Fig. 1B). This control experiment allowed us to pursue our exploration of the BNST-VTA pathway by avoiding a bias in the comparison of the proportion of BNST neurons projecting to the VTA between rat and mice.

The density of BNST neuronal projection to the VTA is stronger in mice than in rats.

We injected the retrograde tracer CTB $(\approx 30 \mathrm{nl})$ in rats $(n=4)$ and mice $(n=5)$ VTA to evaluate the density of BNSTV and BNSTd neurons projecting to the VTA (CTB+ neurons) (Fig. 2). As control, we first compare the proportion of VTA area labelled by CTB injections for mice and rats. To do it, we performed a double immunostaining for CTB and TH, an enzyme of dopamine synthesis, and took measurements on the frontal section showing the most intense injection site for each CTB-injected animal. We observed no significant difference in the proportion of mean hemi-VTA THpositive / CTB-positive cells between mice $(49.23+/-2.4 \%)$ and rats $(53.44+/$ $3.99 \%)\left(\mathrm{t}_{7}=0.844 \mathrm{p}=0.43, \mathrm{~ns}\right)$. More interestingly, our experiments showed that the density of BNSTV and BNSTd neurons projecting to the VTA was significantly higher in mice than in rats (BNSTd: $t_{7}=9.21 p<0.001$; BNSTv: $t=6.044 p=0.005$ ). This difference is clearly observable in neurolucida schematics illustration of BNST retrogradely labelled neurons induced by CTB VTA injection in 4 rats and 4 mice (Fig. 2F-H). Notably, those results suggest that the BNST neuronal population projecting to the VTA is stronger in density, in mice compared to rat, and highlight a difference in the BNST VTA pathway between those two species.

GABAergic and glutamatergic VTA-projecting BNST neurons coexist in rat and mice 
In mice, using combination of retrograde tracing with in situ hybridization, Kudo et al., 2012 have shown that the neurochemical composition of VTA projecting BNST neurons (BNST $\rightarrow$ VTA neurons) is heterogeneous. Most of those neurons express the $67 \mathrm{kDa}$ glutamate decarboxylase (GAD67) but they also found neurons expressing the vesicular glutamate transporters 2 (VgluT2) or 3 (VgluT3). This set of data demonstrates in mice, the coexistence of GABAergic and glutamatergic neurons projecting to the VTA.

To investigate the same question in rats we combined retrograde tracing with laser microdissection and PCR ( $n=6$ rats). Fluorescent microbeads were injected in the VTA (Fig. 3 A-B). The cell body of amBNSTcells positive for microbeads were microdissected (Fig. 3C), and qPCR for CamK2a, GAD67, VgluT2 and VgluT3 were performed on the samples. Control samples of striatum and ovBNST tissues were also analysed and CamK2a qPCR systematically performed. As expected, neurons expressing CamK2a were observed in striatum, ovBNST but also in the rat population of amBNST neurons (BNSTd plus BNSTV) projecting to the VTA (amBNST $\rightarrow$ VTA neurons). As expected, the GABAergic structures used as positive controls (i.e. striatum and ovBNST) present high level of expression for GAD67 and very low levels for the glutamatergic markers VgluT2 and VgluT3 (Fig. 3E). More markedly, we show that amBNST $\rightarrow$ VTA neurons express GABAergic (GAD67) but also glutamatergic markers (VgluT2 and VgluT3) (Fig. 3E) (n of rats ranging from: 2 for tissue analysis to 6 for amBNST $\rightarrow$ VTA cell analysis, CamK2a: ANOVA: $F_{(2,10)}=$ 3.72, $p>0.05$; GAD67: ANOVA: $F_{(2,12)}=0.07, p>0.05$; VgluT2: ANOVA: $F_{(2,12)}=6.39$, $p<0.05$; VgluT3: ANOVA: $F_{(2,5)}=16.41, p<0.05$ ). Kudo and collaborators (Kudo et al., 2012, 2014) data findings taken together with our results, demonstrate that GABAergic but also glutamatergic neurons of the BNST projects to the VTA in both species.

\section{Basal firing rates for VTA DA neurons did not differ between naïve rats and mice}

We did single unit recordings from the VTA in 8 rats and 12 mice under isoflurane anaesthesia. We identified putative DA neurons (denoted hereafter as DA neurons, but see Materials and Methods section for limitations) based on waveform duration 
( $<1.1 \mathrm{~ms}$ to negative trough, $>2.5 \mathrm{~ms}$ for full waveform) and basal firing rate $(<10$ spikes/sec), as reported previously (Grace and Bunney, 1994b; Ungless et al., 2004, Luo et al., 2008). The application of a blue spot (Fig. 2B) at the end of each recording day allowed us to confirm the localisation of recorded cells in the VTA (mostly in the mediolateral part of the VTA, known as the parabrachial pigmented nucleus in rats and mice) (Fig. 4B). We first compared the basal firing rate and the bursting parameters of VTA DA neurons between naive rats and mice (Fig. 4). Interestingly, there was no significant difference between DA neurons in rats vs. mice in terms of mean basal firing rate ( $\mathrm{t}_{90}=1.25, \mathrm{p}=0.21$ ) (Fig. $3 \mathrm{C}$ ) or busting parameters (bursting rate $t_{90}=0.76, p=0.45$; mean spike in burst $t_{90}=0.4, p=0.67$ ) (Fig. 3D). Those data suggest that the basal properties of VTA DA neurons could be the same in rats and mice. In complement to those data, we also did not observe any significant difference in the action potential durations of DA neurons (negative through) between both species (rats : $1.59+/-0.04 \mathrm{~ms}$; mice : $1.36+/-0.03 \mathrm{~ms}$ ).

\section{BNST stimulation: differential early response of VTA DA neurons between mice and rats.}

To compare the BNST-VTA DA monosynaptic pathway between rats and mice, we electrically stimulated the BNST and focused on the early responses $(<15 \mathrm{~ms})$ of VTA DA neurons (Fig. 5). In term of proportion of neurons responding to the stimulation, we found that $88.6 \%$ (39/44) of VTA DA neurons recorded were modulated by BNST stimulation in mice. This number was around $20 \%$ lower in rats $(66.7 \%$ (32 / 48)). On the population of responding neurons, we found early inhibition and excitation in both species. Inhibition was largely represented in mice and rats, with a larger proportion in mice than in rats (rats: $62.5 \%$ (20/32); mice: $84.6 \%$ (33 / 39)). Excited DA neurons were less frequent but more than double in rats vs mice (rats: $37.5 \%$ (12 / 32); mice: 15.4\% (6/39) (Fig. 5C). For the latency of response, rats did not differ from mice for excitation and inhibition (inhibition: $t_{51}=0.86, p=0.4$; excitation $\mathrm{t}_{16}=1.4, \mathrm{p}=0.18$ ) (Fig. $5 \mathrm{D}-\mathrm{E}$ ). Importantly, the mean value for excitatory and inhibitory response latency were largely inferior to $15 \mathrm{~ms}$ (excitation: rat $8.83+$ $1.35 \mathrm{~ms}$, mice: 6 +/- $0.9 \mathrm{~ms}$; inhibition: rat: $3.75+/-1.23 \mathrm{~ms}$, mice $2.6+/-0.72 \mathrm{~ms}$ ), and the jitter for excitatory responses was narrow (Fig. 5D-E). 
Different overall response of VTA DA neuron to BNST stimulation between rats and mice

Using a pre/post stimulation ratio, we evaluated the overall potential effect of BNST stimulation on VTA DA neuronal population. This calculation involved all the DA neurons recorded during BNST stimulation, which included excited, inhibited but also non-responsive neurons. A mean value superior to 1 implied an excitatory effect, while, on the opposite, a value inferior to 1 implied an inhibition (see Materials and Methods section for more details). Intriguingly we observed a significant difference between rats and mice (mean ratio pre/post stimulation (+/- $250 \mathrm{msec}$ ): $t_{69}=2,54, p$ $=0.013$; rat =32 DA VTA neurons; mice: 34 VTA DA neurons). Indeed, a stimulation of BNST induces an early excitation of VTA DA neuronal population in rats (mean ratio pre/post stimulation $(+/-250 \mathrm{~ms})=3.86+/-1.38$, largely superior to 1$)$, whereas it induces a minor early inhibition in mice (mean ratio pre/post stimulation (+/- 250 $\mathrm{ms})=0.69+/-0.1)$. 


\section{Discussion}

As a part of the extended amygdala, the BNST is primarily considered as a key structure for the integration and modulation of fear and anxiety (For review: Daniel and Rainnies 2016; Lebow and Chen 2016). More recently, its role in reward and motivation processes has also been explored, particularly with respect to the VTAprojecting amBNST pathway (Stamatakis et al., 2014). Thereby, the amBNST appears today as central for regulating emotional states and important to understand the link between co-morbid psychiatric diseases such as pathological anxiety, depression and addiction.

Although a contribution of the amBNST in controlling the activity of VTA DA neurons has been clearly established, the functional connectivity between distinct BNST projection neurons and their postsynaptic targets in the VTA remains controversial. In accordance with anatomical data collected by Watanabe group (Kudo et al., 2012, 2014), Stuber and collaborators (Jennings et al., 2013) described a large predominance of GABAergic amBNST neurons projecting to non-DA (putatively GABAergic) neurons in the VTA, with a less predominant glutamatergic projection from the BNST which directly activates VTA DA neurons. This is in contrast with several of our previous studies (Georges and Aston-Jones 2001, 2002; Massi et al., 2008; Jalabert et al., 2009), suggesting a much larger direct impact of glutamatergic BNST efferences on VTA DA neurons.

Comparing these studies, we observed several points of divergence that could explain, at least in part, this disparity. The first point concerns methodological approaches. To investigate the effect of amBSNT stimulation on VTA neurons, the Aston-Jones and Georges groups used in vivo procedures (Georges and AstonJones 2001, 2002; Massi et al., 2008; Jalabert et al., 2009), whereas Jennings et al., 2013, used in vitro preparations. In this latter case, most VTA and BNST afferents are sectioned, producing a loss of network influences. Furthermore, in vitro, evoked BNST glutamatergic EPSCs and GABAergic IPSCs in VTA neurons are observed independently. A second point lies in the use of different animal models, with Georges and Aston Jones using rats, while the other groups utilized mouse models. 
Rodents, especially rats, have historically been the classic animal model for biomedical studies. However, in the last two decades, an important transition has been occurring. The development of a genetic toolbox for mice, leading the development of transgenic mice, has induced a spectacular shift in rodent use, with mouse studies predominating over the use of rats in today's neuroscience research (for review: Ericsson et al., 2013). This transition has advanced discovery in the scientific community, but at the same time begs the question as to whether we can directly compare rat and mouse data? Aside from obvious evolutionary differences, the literature concerning this question is sparse, and although it appears the answer is yes in many cases, striking molecular, anatomical and behavioural differences have been reported in some instances (Ellenbroek and Youn, 2016). In terms of pharmacology, differential distributions of several molecules implicated in addiction or anxiety have been reported between rats and mice. For example, cannabinoid receptors 2 in the VTA and nucleus accumbens are more abundant in rats than in mice (Zang et al., 2015). Furthermore, in mice, the stress hormone corticotropin realising factor (CRF) is more abundant in the lateral septum and in the lateral parabrachial nucleus compared to rats (Wang et al., 2011). On an anatomical level, we can cite a study conducted by Jonckers et al., 2011 where they used resting state functional Magnetic Resonance Imaging (rsfMRI), a method commonly used to study functional connectivity in the brain. Their conclusion suggested a lower interhemispheric functional connectivity in mice than in rats. Finally, striking behavioural differences have been observed between species. Surprisingly, the work of Meijer and collaborators suggests that repeated handling is anxiogenic in mice when it seems anxiolytic in rat (Meijer et al., 2007). Using open field and conditioned place preference paradigms, Kummer et al., 2014 nicely illustrated that social interaction behaviours radically differ, with rats finding social encounters much more appealing than mice. Indeed, they showed that $85 \%$ of rats found social interaction rewarding, compared to mice, where half of them actually found it aversive.

These studies, and several others, suggest that differences in methodology and the choice of rodent model could lead to different results. The present study was undertaken to address these concerns using consistent neuroanatomical and electrophysiological in vivo methodological approaches to compare the BNST projection onto VTA DA neurons in rats and mice. 
Several points of our study revealed fundamental similarities between rats and mice. First, combining retrograde tracing, laser microdissection and q-PCR we observed that, as found in mice (Kudo et al., 2012, 2014), GABAergic and glutamatergic VTA projecting BNST neurons coexist in rats. In a second set of experiments, we then used single cell recordings to reveal that the basal and bursting activity of VTA DA neurons were similar in both species. These observations have, historically, been assumed by the scientific community, but surprisingly, have never been analysed in parallel. These data, therefore, provide the first validation of these assumptions.

On the other hand, we also found divergence between rats and mice. Indeed, our first observation concerned the anatomical VTA-BNST pathway. Using classic retrograde track-tracing we showed that VTA-projecting BNST neurons are more abundant in mice than in rats. Even if this first set of data do not gave us the nature of the BNST neurons projecting to the VTA, it highlights a stronger anatomical BNST-VTA pathway in mice.

The final and main focus of this study concerned the electrophysiological analysis of direct amBNST projection onto VTA DA neurons. To allow such analysis, we used amBNST electrical stimulations (dBNST and vBNST) and focused on the early latency (less than $15 \mathrm{msec}$ ) of response of putative DA neurons. Data on these early responses (excitation or inhibition) strongly suggest that we observed direct monosynaptic connections between amBNST (glutamatergic or GABAergic) neurons and VTA DA cells. Nevertheless, a partial contamination of our data cannot be excluded. For example, some fast di-synaptic connections through VTA GABA interneurons could exist, or we could have recorded some non-dopaminergic neurons which, nevertheless, met the criteria for "dopaminergic electrophysiological parameters" (see material and methods). With regard to the mouse data, we globally found a correlation between Jennings and al., 2016 and our data. Using in vitro procedures and optogenetic stimulation, they found that only $10 \%$ of VTA DA neurons were directly excited by glutamatergic neurons expressing type 2 vesicular glutamatergic transporters (VGlut2). We observed a similar result, with $13.6 \%$ of VTA DA neurons excited by BNST electrical stimulation in vivo. With respect to the crossspecies comparison, according to our parameters, we observed that even though inhibition (GABAergic BNST inhibition of VTA DA neurons) is predominant in mice 
and rats, the excitation (glutamatergic BNST excitation of VTA DA neurons) is more than 3 times more prevalent in rats $(37.5 \%)$ than in mice (15.4\%). Finally, using a pre-post stimulation analysis (see materials and methods for details) including all VTA DA neurons recorded during BNST stimulation, (which included excited, inhibited but also non responsive neurons), we confirmed our previous data. Indeed, we observed an overall BNST stimulating effect on VTA DA neurons in rats compared to a minor inhibition in mice. Collectively, through the observation of similarities and striking differences between rats and mice, this study seems to reconcile previous rat and mouse studies; showing that the excitatory component of the BNST VTA DA pathway is more influential in rats than in mice.

The meaning of the observed dissimilarities between rats and mice with respect to the BNST-VTA pathway remain an open question, but it's appealing to hypothesise that they could underlie some of the differences observed in behaviours requiring a motivational and anxiolytic/angiogenetic component (for review: Ellenbroek and Youn, 2016). For example, we can cite the work of Kummer et al., 2014, where they demonstrate that social interaction with an unknown animal is more anxiogenic for mice than for rats. In the same study, they also observed that in animals concurrently conditioned for social interaction versus cocaine, that the relative reward strength for cocaine was 300 -fold higher in mice than in rats.

Finally, this set of experiments provide inter-species specific basis to reconcile some of the literature inconsistencies on the VTA BNST pathway, but it also highlights the importance of taking into account the choice of animal model for experimental design and interpretation. 


\section{Reference}

Bustin SA, Benes V, Garson JA, Hellemans J, Huggett J, Kubista M, Mueller R, Nolan T, Pfaffl MW, Shipley GL, Vandesompele J, Wittwer CT. The MIQE guidelines: minimum information for publication of quantitative real-time PCR experiments. Clin Chem. 2009 (4):611-22.

Daniel SE, Rainnie DG (2016) Stress Modulation of Opposing Circuits in the Bed Nucleus of the Stria Terminalis. Neuropsychopharmacology 41:103-25. doi: 10.1038/npp.2015.178.

Dong HW, Swanson LW (2004) Organization of axonal projections from the anterolateral area of the bed nuclei of the stria terminalis. J Comp Neurol 468, 277298.

Dumont EC, Williams JT (2004) Noradrenaline triggers GABAA inhibition of bed nucleus of the stria terminalis neurons projecting to the ventral tegmental area. $J$ Neurosci 24, 8198-8204.

Geisler S, Zahm DS (2005) Afferents of the ventral tegmental area in the ratanatomical substratum for integrative functions. J Comp Neurol 490, 270-294.

Georges F, Aston-Jones G (2001) Potent regulation of midbrain dopamine neurons by the bed nucleus of the stria terminalis. J Neurosci 21:RC160.

Georges F, Aston-Jones G (2002) Activation of ventral tegmental area cells by the bed nucleus of the stria terminalis: a novel excitatory amino acid input to midbrain dopamine neurons. J Neurosci 22:5173-5187, pmid:12077212.

Grace AA, Bunney BS (1984a) The control of firing pattern in nigral dopamine neurons: burst firing. J Neurosci 4:2877-90.

Grace AA, Bunney BS (1984b) The control of firing pattern in nigral dopamine neurons: single spike firing. J Neurosci 4:2866-76.

Gungor NZ, Paré D (2016) Functional Heterogeneity in the Bed Nucleus of the Stria Terminalis. J Neurosci 36:8038-49. doi: 10.1523/JNEUROSCI.0856-16.2016.

Ellenbroek B, Youn J (2016) Rodent models in neuroscience research: is it a rat race? Dis Model Mech 9:1079-1087.

Ericsson AC, Crim MJ, Franklin CL (2013) A brief history of animal modeling. Mo Med 110:201-5.

Jalabert M, Aston-Jones G, Herzog E, Manzoni O, Georges F (2009) Role of the bed nucleus of the stria terminalis in the control of ventral tegmental area dopamine neurons. Prog Neuropsychopharmacol Biol Psychiatry 33:1336-46, doi:10.1016/j.pnpbp.2009.07.010. 
Jennings JH, Sparta DR, Stamatakis AM, Ung RL, Pleil KE, Kash TL, Stuber GD (2013) Distinct extended amygdala circuits for divergent motivational states. Nature 496:224-8. doi: 10.1038/nature12041.

Ju G, Swanson LW (1989a) Studies on the cellular architecture of the bed nuclei of the stria terminalis in the rat: I. Cytoarchitecture. J Comp Neurol 280:587-602, doi:10.1002/cne.902800409.

Jonckers E, Van Audekerke J, De Visscher G, Van der Linden A, Verhoye M (2011) Functional connectivity $\mathrm{fMRI}$ of the rodent brain: comparison of functional connectivity networks in rat and mouse. PLoS One 6:e18876. doi: 10.1371/journal.pone.0018876.

Ju G, Swanson LW, Simerly RB (1989b) Studies on the cellular architecture of the bed nuclei of the stria terminalis in the rat: II. Chemoarchitecture. J Comp Neurol 280:603-621.

Kudo T, Uchigashima M, Miyazaki T, Konno K, Yamasaki M, Yanagawa Y, Minami M, Watanabe M (2012) Three types of neurochemical projection from the bed nucleus of the stria terminalis to the ventral tegmental area in adult mice. $\mathrm{J}$ Neurosci 32:18035-46. doi: 10.1523/JNEUROSCI.4057-12.2012.

Kudo T, Konno K, Uchigashima M, Yanagawa Y, Sora I, Minami M, Watanabe M (2014) GABAergic neurons in the ventral tegmental area receive dual GABA/enkephalin-mediated inhibitory inputs from the bed nucleus of the stria terminalis. Eur J Neurosci 39:1796-809. doi: 10.1111/ejn.12503.

Kummer KK, Hofhansel L, Barwitz CM, Schardl A, Prast JM, Salti A, El Rawas R, Zernig G (2014) Differences in social interaction- vs. cocaine reward in mouse vs. rat. Front Behav Neurosci 8:363. doi: 10.3389/fnbeh.2014.00363. eCollection 2014.

Lebow MA, Chen A (2016) Overshadowed by the amygdala: the bed nucleus of the stria terminalis emerges as key to psychiatric disorders. Mol Psychiatry 21:450-63. doi: $10.1038 / \mathrm{mp} .2016 .1$.

Livak KJ, Schmittgen TD. Analysis of relative gene expression data using real-time quantitative PCR and the 2(-Delta Delta C(T)) Method. Methods. 2001;25(4):402-8.

Luo AH, Georges FE, Aston-Jones GS (2008) Novel neurons in ventral tegmental area fire selectively during the active phase of the diurnal cycle. Eur $\mathrm{J}$ Neurosci 27:408-22. doi: 10.1111/j.1460-9568.2007.05985.x.

Massi L, Elezgarai I, Puente N, Reguero L, Grandes P, Manzoni OJ, Georges F (2008) Cannabinoid receptors in the bed nucleus of the stria terminalis control cortical excitation of midbrain dopamine cells in vivo. J Neurosci 28:10496-508. doi: 10.1523/JNEUROSCI.2291-08.2008.

Meijer M K, Sommer R, Spruijt B M, van Zutphen L F M. and Baumans V (2007) Influence of environmental enrichment and handling on the acute stress response in individually housed mice. Lab Anim 41, 161-173. 10.1258/002367707780378168 
Moga MM, Saper CB, Gray TS (1989) Bed nucleus of the stria terminalis: cytoarchitecture, immunohistochemistry, and projection to the parabrachial nucleus in the rat. J Comp Neurol 283:315-332.

Moorman DE, Aston-Jones G (2010) Orexin/hypocretin modulates response of ventral tegmental dopamine neurons to prefrontal activation: diurnal influences. J Neurosci 30:15585-99. doi: 10.1523/JNEUROSCI.2871-10.2010.

Paxinos G, Watson C. The rat brain in stereotaxic coordinates. 6th ed. San Diego: Academic Press; 2007.

Stamatakis AM1, Sparta DR, Jennings JH, McElligott ZA, Decot H, Stuber GD (2014) Amygdala and bed nucleus of the stria terminalis circuitry: Implications for addiction-related behaviors. Neuropharmacology 76 Pt B:320-8. doi: 10.1016/j.neuropharm.2013.05.046.

Ungless MA, Grace AA (2012) Are you or aren't you? Challenges associated with physiologically identifying dopamine neurons. Trends Neurosci 35:422-30. doi: 10.1016/j.tins.2012.02.003.

Ungless MA, Magill PJ, Bolam JP (2004) Science 303:2040-2. Uniform inhibition of dopamine neurons in the ventral tegmental area by aversive stimuli.

Wang L, Goebel-Stengel M, Stengel A, Wu SV, Ohning G, Taché Y (2011) Comparison of CRF-immunoreactive neurons distribution in mouse and rat brains and selective induction of Fos in rat hypothalamic CRF neurons by abdominal surgery. Brain Res 1415:34-46. doi: 10.1016/j.brainres.2011.07.024.

Zhang HY, Bi GH, Li X, Li J, Qu H, Zhang SJ, Li CY, Onaivi ES, Gardner E L, Xi ZX, Liu QR (2015) Species differences in cannabinoid receptor 2 and receptor responses to cocaine self-administration in mice and rats. Neuropsychopharmacology 40, 10371051. 10.1038/npp.2014.297

\section{Figures legends}

Figure 1. BNST neuronal density in rats and mice. $\boldsymbol{A}$, Fluorescent microscopy photographs showing staining for neurons (revealed by fox3, red) (left panel, lowpower view; high-power of area in white box in right panel) in coronal sections trough a rat (top panel) and mouse (bottom panel) BNST. vBNST and dBNST are outlined with white lines. Scale bar: left panel $500 \mu \mathrm{m}$, right panel $50 \mu \mathrm{m}$. B, Bar graph illustrating the density of neurons in the vBNST and dBNST (plotted as density of fox $3+$ neurons by $\mu \mathrm{m}^{3}$ ) in rats and mice. The density of fox $3^{+}$neurons in the vBNST 


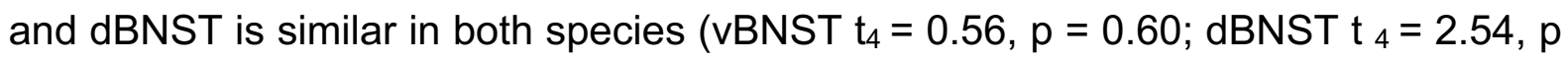
$=0.06 ; n=3$ rats ( 6 hemispheres) and 3 mice ( 6 hemispheres $)$ ).

Figure 2. BNST projection to the VTA in rats and mice. $\boldsymbol{A}$, (top panel) Light microscopy photographs illustrating a VTA CTB injection in rat (left) and mouse (right). (bottom panel) Fluorescence microscopy photographs of staining for BNST neurons projecting to the VTA (injection site showed above, revealed by $\mathrm{CTB}^{+}$ neurons, green), in rat (left) and mouse (right). VTA / BNST and surrounding structures are outlined in black / white. Scale bars: left top picture $1 \mathrm{~mm}$, right top and left bottom pictures $500 \mu \mathrm{m}$, right bottom picture $250 \mu \mathrm{m}$. B, Schematic illustrates local VTA CTB injection protocol and retrograde tracing to the BNST. C, Bar graph revealing the significantly higher density of BNST neurons projecting to the VTA (plotted as density of $\mathrm{CTB}^{+}$neurons by $\mu \mathrm{m}^{2}$ ) in mice than in rats (vBNST $\mathrm{t}_{7}$ $=6.04, \mathrm{p}=0.005 ; \mathrm{dBNST} \mathrm{t}_{7}=9.20, \mathrm{p}<0.001 ; \mathrm{n}=4$ rats and 5 mice $)$. $\boldsymbol{D}$, Light microscopy photographs and schematics illustrating an example of VTA CTB injection and localisation of $\mathrm{CTB}^{+}$neurons throughout the rostro-caudal extent of the BNST in a rat (left panel) and a mouse (right panel). Note that the number of $\mathrm{CTB}^{+}$ neurons is higher in mice than in rats. $\boldsymbol{E}$, Schematics showing the superposition of 4 rats (left panel) and 4 mice (right panel) VTA tracer injections sites and BNST CTB ${ }^{+}$ neurons throughout the rostro-caudal extent of BNST. Observe than the repartition of $\mathrm{CTB}^{+}$neurons throughout the BNST is consistent between animals for the same species and between rats and mice. Landmarks and position from bregma in $\mathrm{mm}$ (adapted from Paxinos and Watson, 2007).

Figure 3. Glutamatergic and GABAergic BNST neurons project to the VTA in rat. $\boldsymbol{A}$, Schematic illustrating the local VTA fluorescent microbeads injection protocol and retrograde tracing to the BNST. $B$, Dark field photograph showing a bilateral injection of fluorescent microbeads in the VTA. Scale bar: $1 \mathrm{~mm}$. $\boldsymbol{C}$, Light microscopy photograph showing a BNST section after dissection of the fluorescent microbeads ${ }^{+}$ neurons (Left photograph), an example of BNST microbeads+ neurons (right photograph) and a schematic representation of a frontal section containing the BNST (bottom right). Left, scale bar: $250 \mu \mathrm{m}$; Right, scale bar: $100 \mu \mathrm{m} . \mathrm{n}=6$ rats $\boldsymbol{D}$, Bar graphs illustrating the presence of CamK2a, GABAergic (GAD67) and glutamatergic (Vglut2 and Vglut3) markers in striatum, ovBNST or amBNST $\rightarrow$ VTA neurons. As 
control, we show that striatum and ovBNST show a high level of expression of CamK2a and GAD67 mRNAs associated to a low level of expression of vGluT2 and vGluT3 mRNAs. In comparison to striatum and ovBNST, amBNST $\rightarrow$ VTA neurons show a similar level of expression of CamK2a and GAD67 and a higher level of expression of vGluT2 $(p<0.05)$ and vGluT3 mRNAs $(p<0.05)$, suggesting that GABAergic and glutamatergic amBNST $\rightarrow$ VTA neurons coexist in rat.

Figure 4. Similar basal tonic activity in rats and mice VTA. $A$, Schematic illustrating VTA DA neural recording. $\boldsymbol{B}$, Photograph of a frontal section (neutral red stain) showing a pontamine sky blue deposit that marks a recording site in a rat (left) and mouse (right) VTA. Scale bar: $500 \mu \mathrm{m}$. C, Bar graph showing that the mean basal firing rate of VTA DA neurons in rats and mice are similar $\left(t_{90}=1.25, p=0.21\right)$. $D$, Analyses of VTA DA neuron busting activity. Bar graphs show that bursting activity is similar between VTA DA neurons in rats and mice (bursting rate: t $90=0.75$, $p=0.45$; mean spike per burst: $t_{90}=0.40, p=0.68$ ). For all figures: rats: $n=48$ cells, 8 rats; mouse: $n=44$ cells, 12 mice.

Figure 5. Different VTA early response to BNST stimulation between rats and mice. $A$, Schematic illustrates local BNST electrical stimulations $(0.5$ to $1.5 \mathrm{~mA}$ pulse, $0.5 \mathrm{~Hz}, 100$ repetition) during VTA DA neural recording. $\boldsymbol{B}$, (left panel) Schematics showing the localization of each BNST electrical stimulation in rats (top) and mice (bottom). (right panel) Photographs of frontal sections (neutral red stain) showing the placement of a stimulating electrode in a rat (top) and a mouse (bottom) BNST (revealed by electrolytic lesion at the end of a recording day). Scale bar: 1 mm. Landmarks adapted from Paxinos and Watson, 2007. Rats: $n=8$; mice: $n=12$. $C$, Pie charts represent the fraction of VTA DA recorded neurons responding (early response $<15 \mathrm{~ms}$ ) to BNST stimulation by an excitation or an inhibition in rats and mice. Note that even if the majority of responding DA VTA neurons are inhibited in both species, the proportion of DA VTA excited neurons in more than double in rats than in mice. $\boldsymbol{D}$, Illustration of VTA DA excited neurons (early responses $<15 \mathrm{~ms}$ ) by BNST stimulation. $\mathbf{D}_{1}$, Bar graph representing the mean latency of excited neurons in rats and mice. There is no significant differences between both species $\left(t_{16}=1.39, p\right.$ $=0.18$ ) rats: 12 cells, mice: 6 cells. $\boldsymbol{D}_{2}$, Perievent stimulus-time histogram (PSTH) 
and raster plot illustrating a typical example of a rat (left) and a mouse (right) VTA DA neuron excited by BNST stimulation (at time 0). D3, Examples of 5 superimposed traces (centered on the stimulation artefact) from a rat (left) and a mouse (right) VTA DA neuron excited by BNST stimulation. The examples show the typical short latency onset of the excitation. $E$, Illustration of VTA DA inhibited neurons (early responses $<15 \mathrm{~ms}$ ) by BNST stimulation. $\boldsymbol{E}_{1}$, Bar graph representing the mean latency of inhibited neurons in rats and mice. There is no significant difference between both species $\left(t_{51}=0.86, p=0.39\right)$. $E_{2}$, PSTH and raster plot illustrating a typical example of a rat (left) and mouse (right) VTA DA neuron inhibited by BNST stimulation (at time 0 ). $\boldsymbol{E}_{3}$, Examples of 5 superimposed traces (centered on the stimulation artefact) from a rat (left) and mouse (right) VTA DA neuron inhibited by BNST stimulation.

Figure 6. Global potential response of VTA DA neuronal population to BNST stimulation. $A$, Schematics illustrating the methods used to analyse the global effect of BNST stimulation on VTA DA neuronal population. $B$, Bar graph representing the global effect of BNST stimulation on VTA DA neurons. The mean ratio pre/post stimulation is significantly different between rats and mice ( $t_{69}=2.53, p=0.39$; rats $n$ = 32 VTA DA neurons; mice: 34 VTA DA neurons). BNST stimulations induced a global early excitation on VTA DA neurons in rats (mean ratio pre/post stimulation = $3.86+/-1.38$ ) and a minor inhibition in mice (mean ratio pre/post stimulation $=-0.69$ $+/-0.1$. 
Figure 1
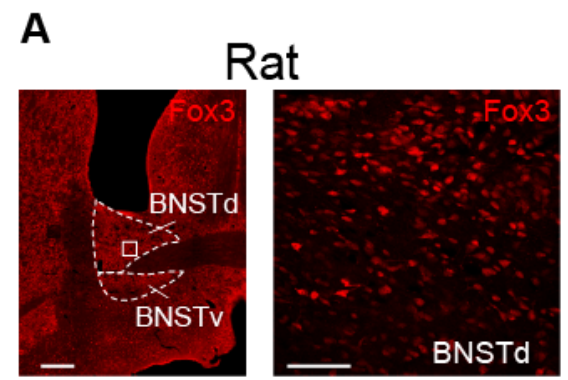

Mouse

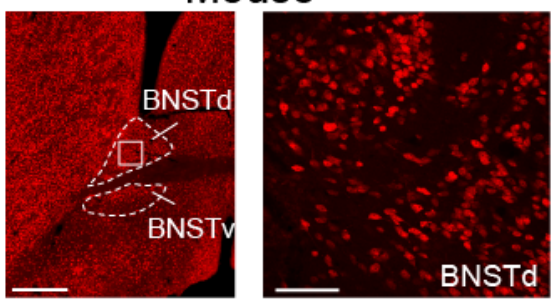

B

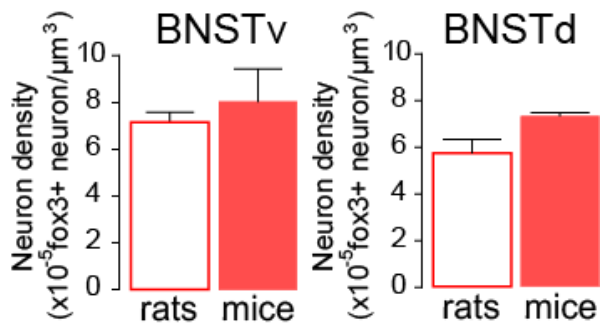




\section{Figure 2}

A
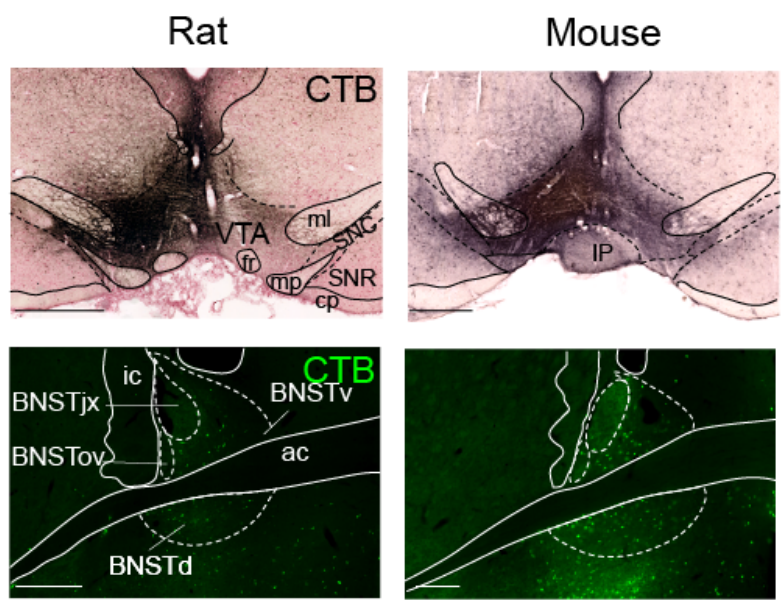

D

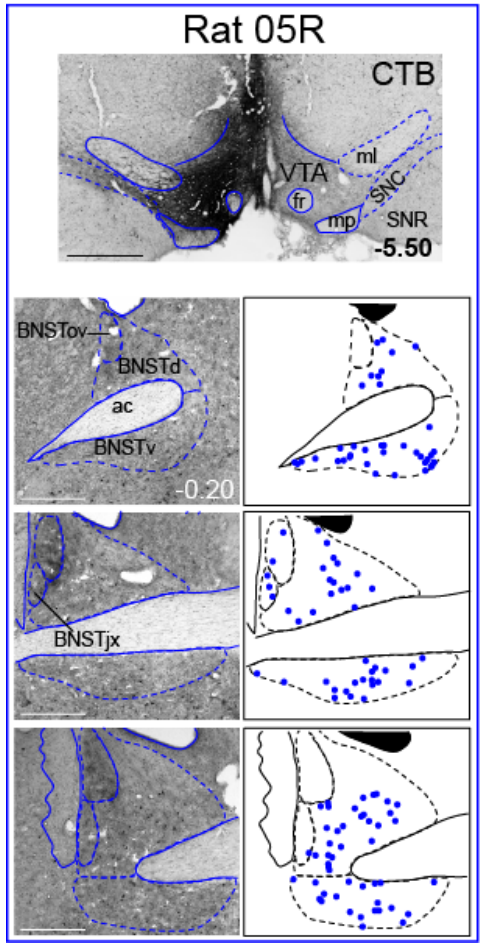

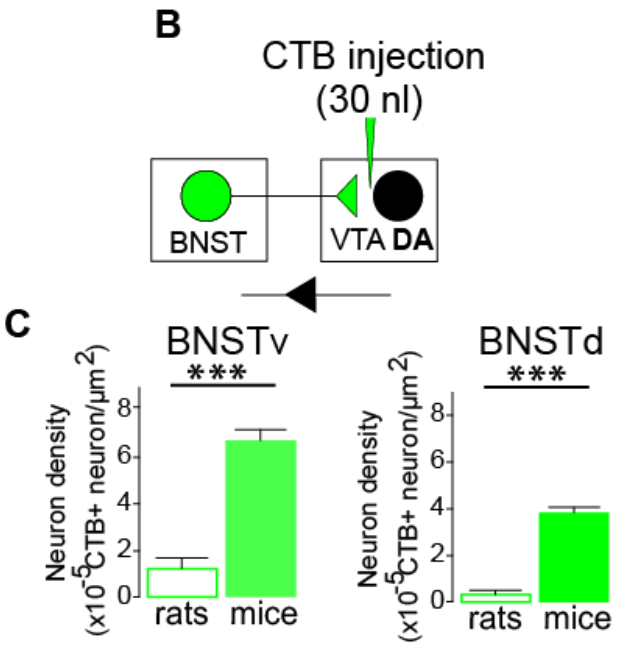

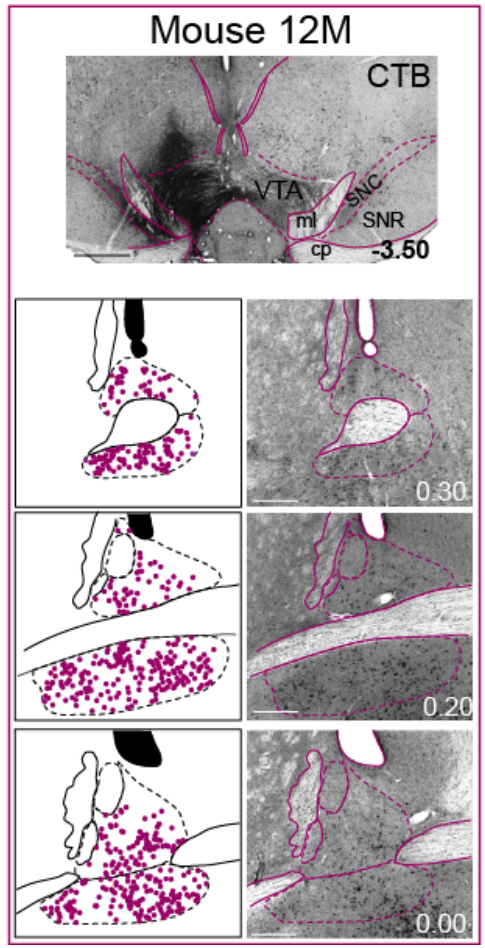

E

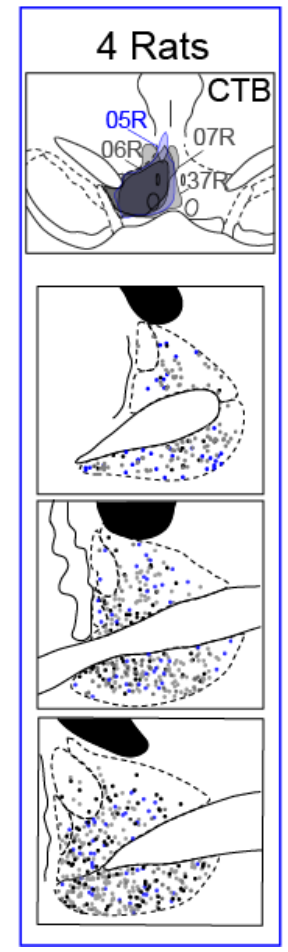

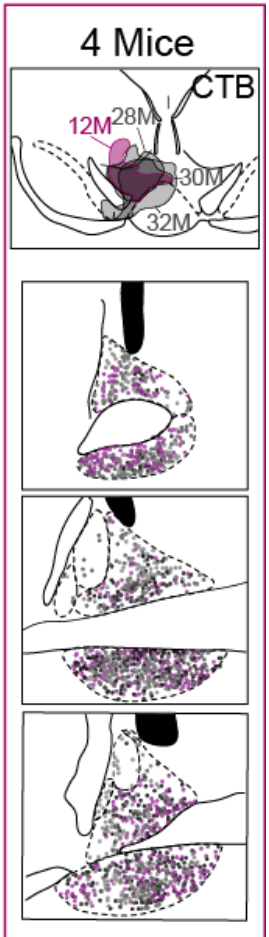


Figure 3
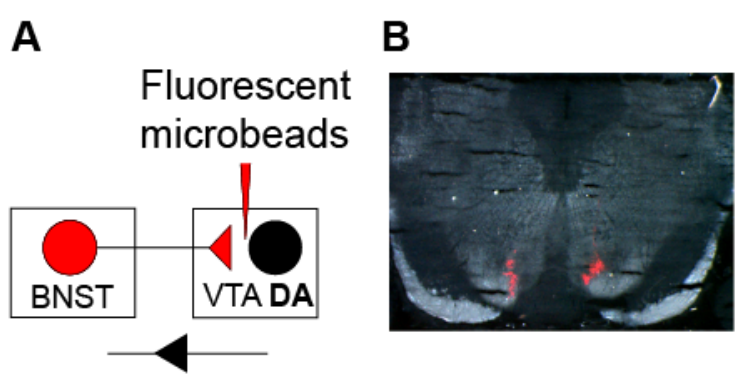

C

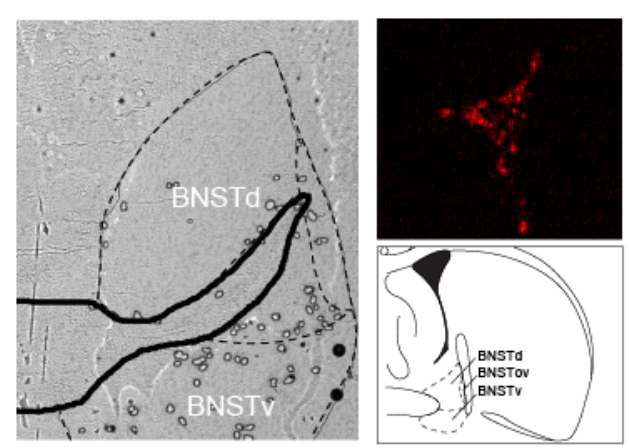

\section{D}
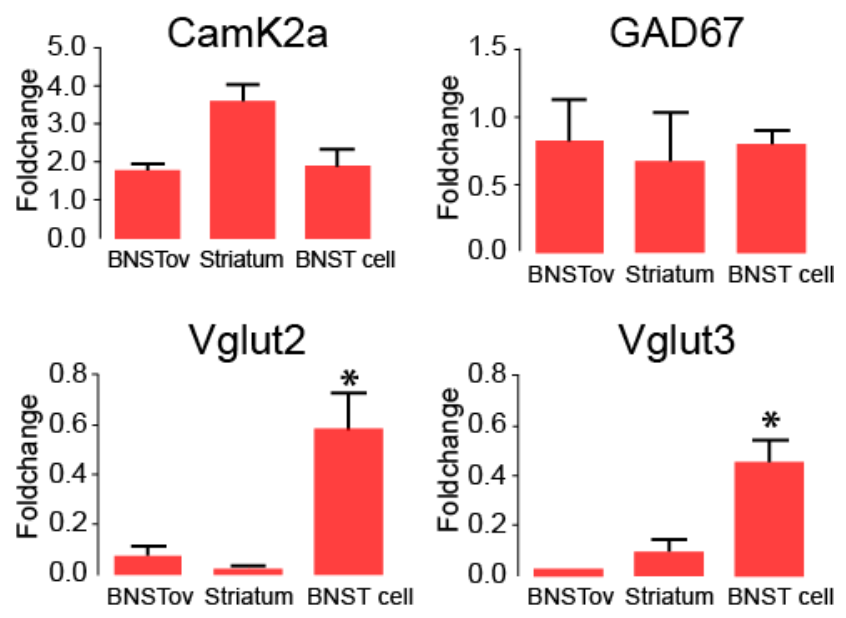
Figure 4

A

B Rat

Mouse
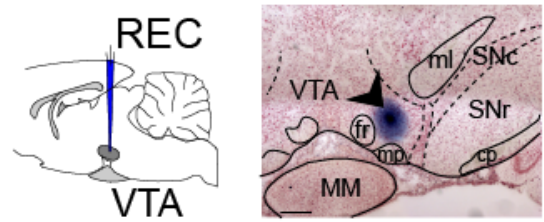

C

\section{C}
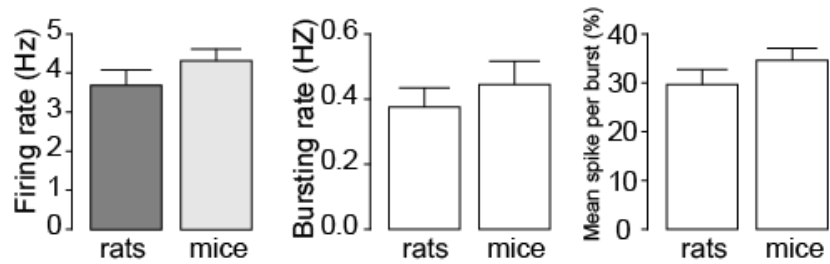
Figure 5

A

$0.5 \mathrm{~Hz} 0.5 / 1.5 \mathrm{~mA}$

100x תRू REC

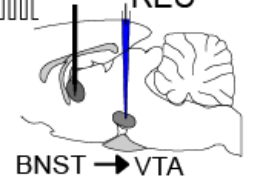

B
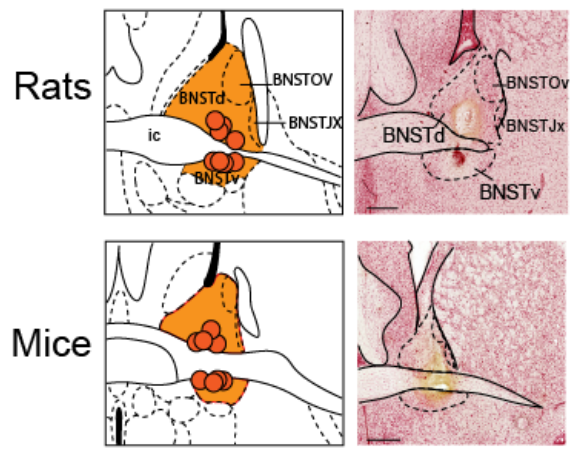

C
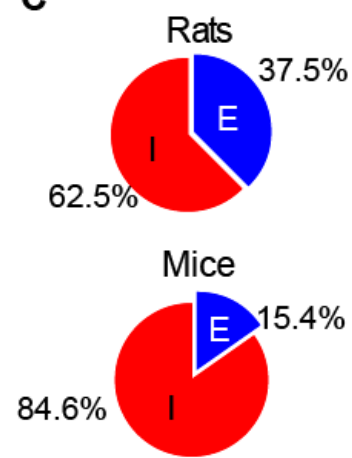

D

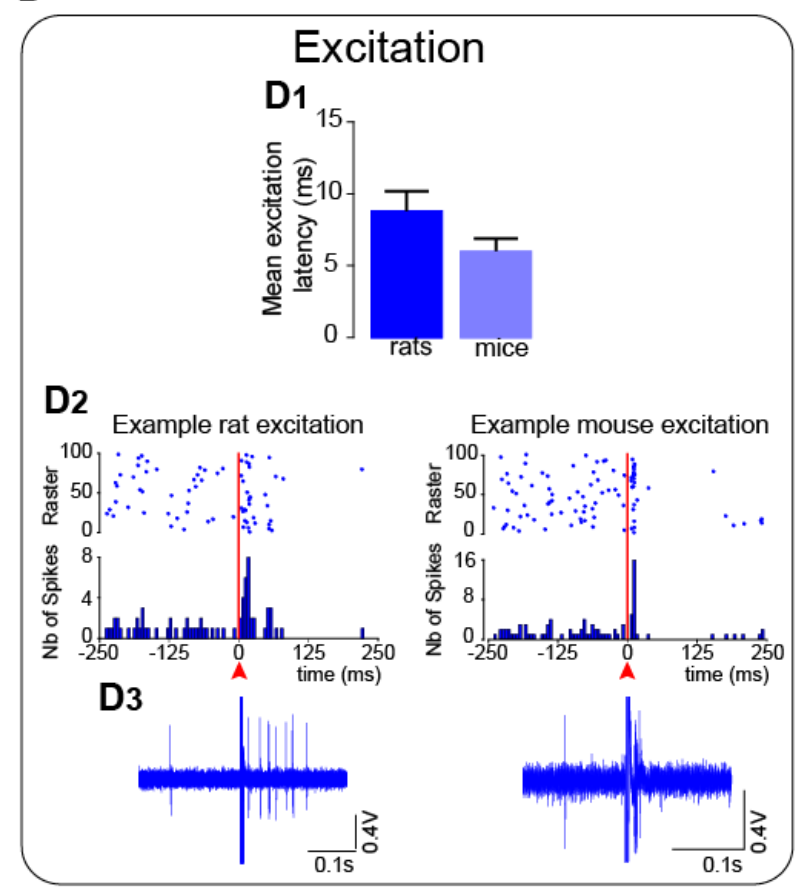

E

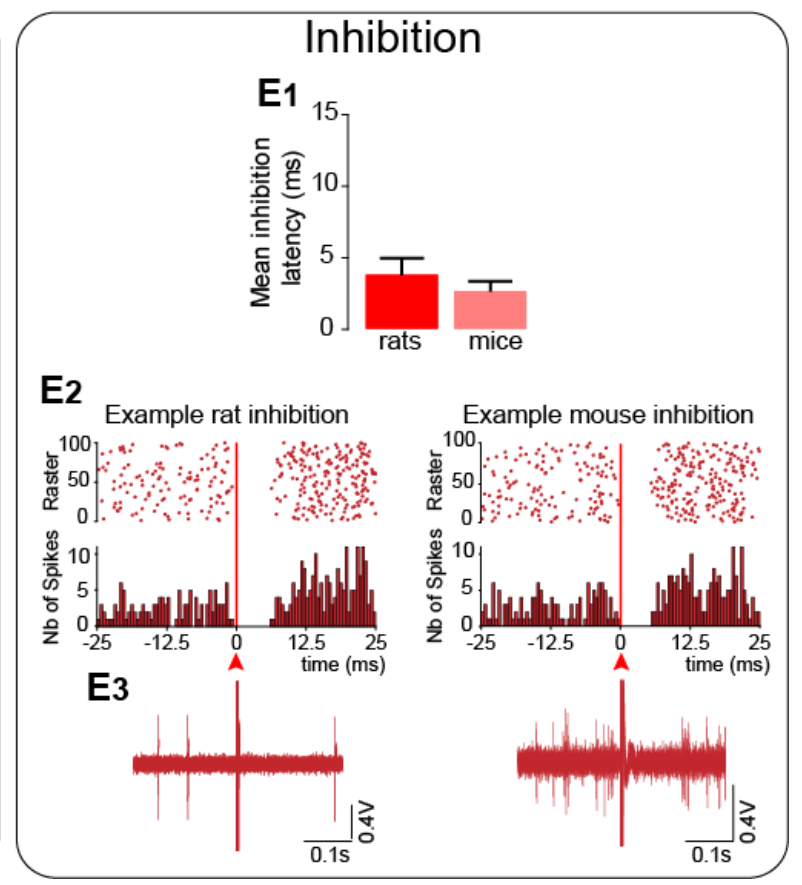


Figure 6

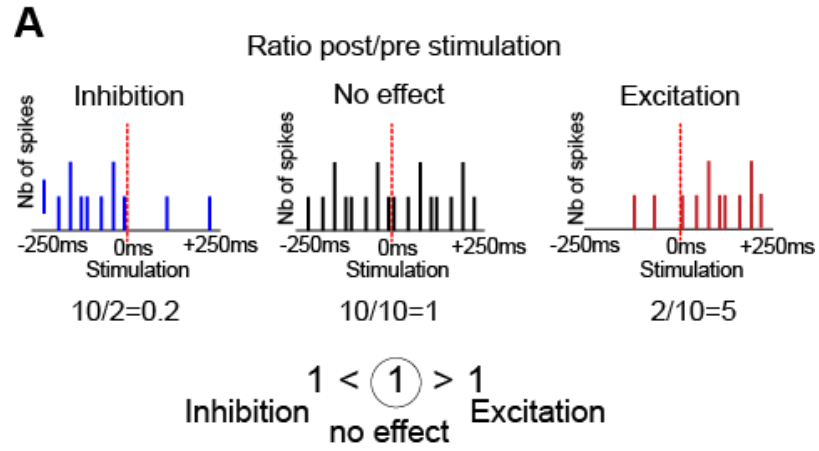

B

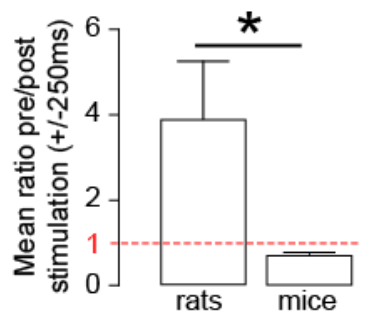


